\title{
PESQUISA E ENSINO DE ESCRITA: LETRAMENTO ACADÊMICO E ETNOGRAFIA
}

\author{
Writing teaching and research: academic literacy and \\ ethnography
}

Raquel Salek FIAD

Resumo | Apresento, neste artigo, uma perspectiva etnográfica como embasamento para a pesquisa sobre escrita acadêmica e também para o ensino de escrita acadêmica. Para isso, inicialmente, confronto essa perspectiva com a tradição de pesquisas e de ensino de escrita embasada em teorias textuais e discursivas, que é a predominante no contexto brasileiro. Em seguida, apresento diferentes possibilidades de se usara etnografia na pesquisa sobre escrita acadêmica, mostrando seus ganhos e limites, e defendo a possibilidade de se assumir a etnografia como teoria, como perspectiva de análise da linguagem. A noção de indexicalização é fundamental nessa abordagem proposta. Finalmente, apresento consequências para um ensino de escrita também embasado em uma perspectiva etnográfica como teoria.

Palavras-chave | Letramento acadêmico. Etnografia. História do texto. Pesquisa sobre escrita acadêmica. Ensino de escrita acadêmica.

\begin{abstract}
In this paper, I present an ethnographic perspective as basis for both academic writing research and teaching. In the first part, I present the traditional writing research and teaching perspective based on textual and discursive theories, which is the predominant perspective in Brazilian researches. Afterwards, I present different ways of understanding ethnography and I defend the perspective that considers ethnography as a theory. This perspective has the notion of indexicality as an important concept for analysis. Finally I discuss how ethnography can be a basis for writing teaching.

Keywords | Academic literacy. Ethnography. Text history. Academic writing research. Academic writing teaching.
\end{abstract}

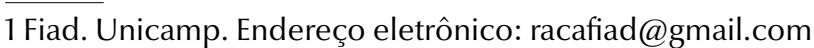


- Pesquisa e ensino de escrita: letramento acadêmico e etnografia

\section{Introdução}

O objetivo deste texto é apresentar algumas reflexões a partir da leitura de pesquisas sobre a escrita, especialmente sobre a escrita acadêmica (mas que podem ser estendidas a outras escritas) que têm uma abordagem etnográfica orientada pelo texto².

Refiro-me principalmente aos trabalhos desenvolvidos por Lillis (2008, 2009), Lillis e Curry (2010) e Ivanic (1998) que nos apresentam uma discussão produtiva sobre a presença da etnografia em pesquisas sobre a escrita. Conforme defendido por Lillis (2008), com base em Blommaert (2006), podemos considerar a presença da etnografia como uma perspectiva não só metodológica, mas também teórico-metodológica, ponto que será retomado mais adiante.

Sigo o seguinte caminho na organização deste texto: (1) recupero brevemente nossa tradição de pesquisas sobre escrita escolar, orientada por teorias de texto e de discurso e mostro como os estudos do letramento se apresentam como outra opção teórica; (2) mostro a perspectiva dos estudos dos letramentos, mais especificamente dos Novos Estudos do Letramento e os desdobramentos para a pesquisa ao se considerar a etnografia como uma opção teórica; (3) apresento aspectos de uma perspectiva etnográfica que podem ser desdobrados em propostas de ensino de escrita.

\section{Estudos sobre a escrita}

Em seu artigo "A constituição da escrita escolar em objeto de análise dos estudos linguísticos", Pietri (2007) mostra que os estudos acadêmicos sobre a escrita escolar, com base em teorias linguísticas, começaram a ser realizados, no Brasil, no final da década de 70, no que ele denomina de período de emergência da redação escolar como objeto de pesquisa. Adota uma perspectiva discursiva para analisar a constituição desse objeto de pesquisa e defende que "a constituição desse objeto se realizou em função de relação polêmica entre perspectivas fundamentadas nos conhecimentos da Linguística e perspectivas fundamentadas nos estudos tradicionais de linguagem" (PIETRI, 2007, p. 283).

Dessa análise de Pietri, destaco dois pontos: (1) a fundamentação teórica para uma parte dos estudos sobre escrita escolar (feitos, nesse momento, com base na escrita em situação de vestibular) é a gramática normativa e, frequentemente, os problemas

2 Tradução de "text-oriented ethnographic approach", expressão usada por Lillis e Curry (2010, p. 25). 
encontrados nas redações, são atribuídos à incapacidade linguística dos estudantes; (2) um outro conjunto de estudos dessa fase tem como base teorias linguísticas, distanciando-se da tradição normativa e deslocam a causa dos problemas da incapacidade dos alunos. Segundo Pietri (2007, p. 292), Pécora (1977) e Osakabe (1977), cujos estudos representam a pesquisa sobre escrita nesse momento, defendem que "a ocorrência de problemas lingüísticos nas redações, para ser compreendida, segundo o artigo, precisa ser relacionada a fatores de outra ordem que não os relativos ao conhecimento especificamente linguístico que possui o vestibulando" (PIETRI, 2007, p. 292).

Nessa fase de emergência, portanto, já foram introduzidas, nos estudos sobre textos escolares, em nosso contexto, teorias do texto e do discurso. Em um breve levantamento visando um estado da arte de pesquisas sobre aquisição e ensino da escrita no Brasil, observamos um predomínio significativo do referencial teórico com base em teorias do discurso (CARON et al., 2000).

Esses dois estudos nos dão uma amostra da nossa breve tradição em pesquisas sobre escrita escolar. Essa tradição de pesquisas teve e tem forte influência no ensino de português na escola brasileira, como pode ser constatado através dos documentos oficiais produzidos nas últimas décadas. O texto como objeto de ensino foi uma das grandes mudanças presentes na organização do ensino de português nas décadas de 80 e 90, como mostramos em artigo publicado em 1996 (GERALDI; FIAD; SILVA, 1996). Em seguida, os gêneros do texto e do discurso ocuparam esse lugar central, desde a publicação da primeira versão dos Parâmetros Curriculares Nacionais no final da década de 90. Essa imbricação entre o domínio acadêmico-científico e o domínio do ensino é bem demonstrada em relação ao conceito de gênero (de texto, de discurso) por GomesSantos (2004).

Até aqui, venho falando da pesquisa e do ensino da escrita escolar e não propriamente da escrita acadêmica. Isso por algumas razões. A pesquisa sobre a escrita acadêmica e sobre o seu ensino é bem recente no Brasil e não conheço nenhum levantamento sobre as tendências nessas pesquisas. Tudo nos leva a pensar nas mesmas bases teóricas textuais discursivas para essa análise. Não é diferente do que aponta Lillis (2008) em relação à pesquisa sobre escrita acadêmica, com base em levantamentos realizados por pesquisadores da área: "Um objeto principal da pesquisa sobre escrita acadêmica tem sido, e continua a ser, o texto escrito. Existe uma tradição longa e variada de abordagens com foco no texto, com apoio na retórica, em diferentes modelos linguísticos e em estudos de gêneros diversos" (LILLIS, 2008, p. 354, tradução nossa) ${ }^{3}$.

3 A principal object of academic writing research has been, and continues to be, the written text. There is a long and varied tradition of text-focused approaches to academic writing, drawing on rhetoric, a range of linguistic frameworks, and diverse genre studies. 
- Pesquisa e ensino de escrita: letramento acadêmico e etnografia

Ao lado dessa tradição textual-discursiva tanto na pesquisa sobre a escrita como nas orientações voltadas ao ensino da língua, no cenário brasileiro, na década de 80 , o conceito de letramento entra nas discussões acadêmicas e educacionais. Como já disse anteriormente,

Resumindo a inserção do conceito a partir da década de 1980, podemos dizer que o conceito de letramento passa a fazer parte das discussões educacionais no país, dialogando com o conceito de alfabetização, em si já polêmico, principalmente quando se trata de estabelecer critérios entre o alfabetizado e o analfabeto. (FIAD, 2015, p. 25)

Compartilho a crítica feita por Andrade (2010, p. 5) ao modo como o conceito de letramento foi apresentado ao contexto educacional, especialmente aos profissionais da alfabetização:

\begin{abstract}
Na década de 90, desembarca no campo da educação uma perspectiva teórica sobre a língua escrita, sob o rótulo de estudos de Letramento. Estes já vinham sendo desenvolvidos em diversas áreas das ciências humanas (Antropologia, Estudos Etnográficos, História Cultural, Sociologia da leitura), mas no Brasil os caminhos que tomaram rumavam para a disposição de dialogar com o que vinha sendo feito em termos de alfabetização nas escolas.

Na difusão do conceito, vinha pressuposta a separação entre os processos de alfabetização e de letramento, e preconizandose sua junção. Dizia-se que "deve-se alfabetizar letrando", o que pressupostamente implica em se pensar que estes processos andavam até aquele momento separados. Por se ter focalizado nesta dicotomização, buscando-se didaticamente indicar a separação dos termos alfabetização e letramento para preconizar a sua junção, os efeitos que se acabou provocando foram indesejáveis, os de não entendimento da relevância da perspectiva em si.
\end{abstract}

$\mathrm{Na}$ época em que o conceito de letramento iniciou sua grande inserção no contexto educacional brasileiro, estudiosos como Street (1984), Barton (1994) e Gee (1996) já propunham uma visão de letramento como um fenômeno social, distanciandose da concepção mais calcada no indivíduo e apoiada em crenças e concepções que 
começaram a ser relativizadas e criticadas. Essa tradição conhecida como Novos Estudos do Letramento ficou paralela à tradição textual-discursiva hegemônica.

Na próxima seção, apresento estudos que tentam romper com essa separação. São estudos derivados dos Novos Estudos do Letramento e que defendem a etnografia como uma opção teórica e metodológica de trabalho com o texto.

\section{Novos estudos do letramento, letramento acadêmico e etnografia}

Opondo-se à concepção dicotômica entre oralidade e escrita, questionando a visão de que a presença da escrita provocaria impactos e consequências nas sociedades e nos indivíduos, derrubando a crença na supremacia da escrita e das sociedades que possuíam a escrita em oposição às sociedades ágrafas, foi proposto o que alguns estudiosos - Street (1984), Barton (1994) e Gee (1996), dentre outros - denominaram Novos Estudos do Letramento (NEL).

Street (1984), um dos autores responsáveis por essa concepção de letramento, apresenta críticas à concepção de escrita da cultura ocidental, que privilegia os gêneros do discurso das classes dominantes, deixando à margem outros gêneros. Essa concepção considera a escrita e a leitura como neutras, independentes dos processos sociais, históricos e culturais.

Os Novos Estudos do Letramento, em contraposição a essas concepções, entendem o letramento como prática social, dependente dos contextos sociais nos quais a língua escrita se inscreve. Esse modelo entende que há diferentes usos sociais da linguagem e que os significados atribuídos à escrita e à leitura são dependentes dos contextos sociais. Consequentemente, não há um letramento, mas letramentos, a depender dos significados atribuídos por diferentes grupos sociais. Essa concepção de letramento é sustentada a partir de estudos etnográficos realizados em vários contextos no mundo e é distinta do que Street denomina de modelo autônomo do letramento, que privilegia as habilidades técnicas, supostamente uniformes em todos os contextos. Essa distinção estabelecida vai ser fundamental para as discussões em contextos de ensino de linguagem, desde a alfabetização até o contexto universitário, que é o foco deste texto.

A partir da concepção do letramento como um conjunto de práticas sociais situadas - desenvolvida no interior dos NEL - alguns estudiosos começaram a focar o contexto acadêmico, com o objetivo de compreender as práticas aí presentes, compreendendo que há práticas específicas desse contexto, dada a concepção de múltiplos letramentos. Esse foco de estudos ganhou grande impulso em vários centros de pesquisa não só por 
- Pesquisa e ensino de escrita: letramento acadêmico e etnografia

razões inerentes à concepção de letramentos múltiplos, mas também por motivações políticas e sociais, destacando-se a expansão do ensino superior, tanto em quantidade de alunos, como principalmente em diversidade cultural e linguística (FIAD, 2013).

Nessa perspectiva, então, a escrita acadêmica é uma prática social. Conforme Lillis e Curry (2010, p. 19, tradução nossa),

\begin{abstract}
Uma abordagem ao letramento como prática social concebe leitura e escrita como atividades fundamentalmente sociais [...] prática sinaliza que usos específicos de linguagem - textos falados e escritos não existem isoladamente mas estão ligados ao que as pessoas fazem - práticas - no mundo material, social ${ }^{4}$.
\end{abstract}

Lillis (2008) aponta que, ao lado da tradição textual discursiva, foi crescendo um interesse de pesquisas com foco no contexto da escrita, com o objetivo de entender o que está envolvido na escrita acadêmica. Ela atribui esse interesse tanto a preocupações de ordem pedagógica (já que há uma tradição de ensino de escrita em universidades de vários países) que se defronta com um discurso de crítica à escrita de estudantes, como ao crescimento da consciência geopolítica que rege a escrita acadêmica para publicações. Deslocar a análise dos textos para as práticas é coerente com a perspectiva dos NEL, que exploram amplamente as práticas de letramentos em diferentes contextos.

Ainda segundo Lillis (2008), a etnografia ocupa um lugar importante nas abordagens à escrita acadêmica que se preocupam com o contexto. Um exemplo em que essa presença da etnografia é defendida e explicitada são as pesquisas desenvolvidas na perspectiva chamada de letramentos acadêmicos, principalmente no Reino Unido e em seguidores em outras partes. Nessas pesquisas, o letramento é assumido como prática social e as metodologias adotadas estão baseadas na tradição da etnografia.

No entanto, as perguntas que podem ser feitas são: como a etnografia está presente em pesquisas sobre escrita? Quais os limites e ganhos com a etnografia nessas pesquisas? Afinal, o que é a etnografia nessas pesquisas?

A distinção que Lillis (2008) apresenta entre etnografia como método, etnografia como metodologia e etnografia como teorização nos ajuda a entender como diferentes pesquisas têm utilizado a etnografia de modos distintos. Apresento brevemente essas

4 A social practice approach to literacy conceptualizes reading and writing as fundamentally social activities [...] practice signals that specific instances of language use - spoken and written texts - do not exist in isolation but are bound up with what people do - practices - in the material, social world. 
distinções, destacando alguns aspectos característicos de cada possibilidade, além de seus limites e ganhos para as pesquisas.

Etnografia como método acontece geralmente através de entrevistas, chamadas de conversas sobre o texto ${ }^{5}$, em um contínuo texto-escritor, em que o ponto de partida tanto pode ser o texto como o escritor. No primeiro caso, o foco é o texto e a conversa sobre ele é considerada em segundo plano, sendo a análise conduzida com base na tradição textual discursiva prioritariamente. No segundo caso, o foco é no escritor e a análise considera a sua perspectiva para entender a escrita, possibilitando reflexões sobre as diferentes formas como a escrita é produzida e significada. O ganho deste uso da etnografia é possibilitar ao pesquisador um olhar além do texto, com um deslocamento para as perspectivas do escritor. No entanto, há limites, principalmente se for uma única entrevista, especialmente pelo risco de se cair em uma simplificação do que é dito pelo escritor e em tratar como transparentes as reflexões do escritor.

A etnografia como metodologia inclui uma variedade de dados além da conversa sobre o texto e pressupõe um envolvimento maior com os escritores, tanto em tempo como em quantidade de informações. Lillis (2008) propõe conversas cíclicas sobre o texto (envolvendo análise e discussões sobre o texto) com os escritores, associadas à entrevista sobre história de letramento, além de outros dados como trocas de e-mails entre o pesquisador e o escritor, correspondências entre o escritor e mediadores do letramento ${ }^{6}$ e análise de documentos institucionais. O conceito de história do texto é usado para esse conjunto de dados que mostra a trajetória de textos. Esse é o ganho dessa metodologia: os diferentes dados que constituem a história do texto possibilitam entender o impacto do contexto nos textos em suas trajetórias. O pesquisador ganha um envolvimento com os escritores e vai conseguindo informações que só são possíveis nesse percurso; o pesquisador como etnógrafo vai se inserindo mais no campo, vai formulando novas perguntas e adquirindo novas compreensões. A natureza cíclica das conversas sobre o texto permite ao pesquisador trazer suas análises para o escritor, discuti-las, ouvir o escritor e assim por diante.

Os estudos que usam essa metodologia se baseiam em longos acompanhamentos de escritores na produção de textos, envolvendo as trocas entre eles e os mediadores do letramento. Mesmo com todos esses ganhos, nessa metodologia, além do risco já

5 Lillis (2009) apresenta conversas sobre o texto, metodologia proposta por Ivanic (1998), e mostra como essa metodologia influenciou suas pesquisas.

6 Lillis e Curry (2010) usam a expressão literacy brokers para as diferentes pessoas que impactam os textos acadêmicos em suas trajetórias. Dentre esses, podemos incluir revisores, pareceristas, editores, colegas leitores. 
- Pesquisa e ensino de escrita: letramento acadêmico e etnografia

mencionado de se interpretar como transparentes as reflexões do escritor, Lillis aponta que permanecem, texto e contexto, sendo tratados separadamente. Mesmo diminuindo a separação entre ambos, ainda assim as categorias de análise textual são tratadas paralelamente aos aspectos contextuais.

Para superar essas limitações, é necessário pensar a etnografia não como um conjunto de técnicas. Como diz Blommaert (2006, p. 3, tradução nossa), "Uma primeira correção a ser feita à imagem difundida de etnografia é que, desde seu começo, a etnografia foi mais do que um conjunto de técnicas de trabalho de campo"7. Opondo-se a essa visão, esse autor defende que etnografia "envolve uma perspectiva sobre linguagem e comunicação, incluindo uma ontologia e uma epistemologia, sendo ambas significativas para o estudo da linguagem na sociedade, ou melhor dizendo, da linguagem bem como da sociedade" (BLOMMAERT, 2006, p. 2, tradução nossa) ${ }^{8}$.

No nível epistemológico, "o conhecimento de fatos da linguagem é um conhecimento processual e histórico, trazendo instâncias de uso da língua a um nível de relevância maior do que o evento em si" (BLOMMAERT, 2006, p. 6, tradução nossa) ${ }^{9}$. Essa é a noção de indexicalização, retomada por Lillis (2008) como proposta para a pesquisa de escrita acadêmica. Desse modo, extratos de linguagem indexicalizam ou apontam para aspectos do contexto social. Essa noção ajuda o pesquisador a relacionar as visões do escritor e as dele próprio a estruturas sociais maiores. Segundo Lillis (2008, p. 381, tradução nossa):

A atenção ao micro detalhe envolve um reconhecimento explícito da importância da relação entre as dimensões êmica e ética. Prestar atenção aos detalhes microtextuais e contextuais da escrita acadêmica é relevante porque eles podem nos ajudar a explorar a política complexa da produção de escrita acadêmica ${ }^{10}$.

\footnotetext{
7 A first correction that needs to be made to the widespread image of ethnography is that right from the start, it was far more than a complex of field work techniques.

8 Involves a perspective on language and communication, including an ontology and an epistemology, both of which are of significance for the study of language in society, or better, of language as well as of society.

9 Knowledge of language facts is processual and historical knowledge, lifting single instances of talk to a level of relevance far higher than just the event.

10 Attention to microdetail involves an explicit recognition of the importance of the interplay between emic and etic dimensions. The relevance of paying attention to microtextual and contextualized details of academic writing is that they can help us explore the complex politics of academic text production.
} 
Essa compreensão de etnografia como teoria, discutida por Blommaert (2006) e Lillis (2008), recupera a etnografia em suas origens na antropologia, enfatizando a não separação entre língua e cultura, entre texto e contexto. Nessa tradição antropológica, não existe linguagem sem contexto. A separação entre texto e contexto na pesquisa sobre escrita acadêmica (e sobre a escrita em geral) vem das abordagens linguísticas sobre a escrita e da força que essa tradição tem.

Em alguns de seus estudos sobre escrita acadêmica, Lillis (2008) mostra que o estudo do texto, isolado de conhecimentos sobre o contexto, não nos permite entender por que alguns estilos de escrita são ou não aceitos em determinados contextos nem a relação entre esses estilos e os contextos em que são produzidos. A noção de indexicalização ajuda a relacionar o texto a aspectos contextuais recuperados através das histórias do texto.

Reconhecer a etnografia como teoria, como perspectiva de análise da linguagem, é ir além da perspectiva de metodologia como método. Essas distinções são relevantes para orientar as pesquisas sobre escrita para que se tenha a real dimensão do que as diferentes perspectivas possibilitam como análise. Quanto a isso, é inegável reconhecer as dificuldades práticas de se empreender pesquisas nessa dimensão, não só devido ao trabalho e envolvimento necessários para um acompanhamento de escritores por um período longo, mas também quanto aos desafios para a análise, já que o pesquisador, para tentar entender o que é significativo para os escritores, terá que sair, frequentemente, de sua zona de conforto disciplinar. E pesquisas produzidas nessa dimensão certamente não responderão à imediatez de resultados esperada atualmente no contexto científico.

\section{Etnografia na pesquisa e no ensino}

Começo esta última seção do artigo - que tem um caráter propositivo - com a sugestão de Blommaert (2006) sobre o caráter crítico, questionador e desafiador da etnografia, que pode ser compreendido tanto para a pesquisa sobre escrita acadêmica como para as possibilidades de ensino dessa escrita. Blommaert diz que a etnografia tem o potencial de desafiar visões consagradas, não apenas da linguagem, mas do capital simbólico na sociedade.

A etnografia permite essa perspectiva, que Blommaert chama de anti-hegemônica, especialmente para discutir e analisar a escrita acadêmica que foge aos padrões esperados, o que é muito frequente especialmente devido aos padrões rigorosos que regem essa escrita. Essa situação é vivida não só por estudantes, mas também por acadêmicos ao terem suas escritas lidas e avaliadas em inúmeras situações de avaliação acadêmica. Tanto 
- Pesquisa e ensino de escrita: letramento acadêmico e etnografia

a situação do estudante como a do acadêmico são complexas, pois envolvem normas, padrões, instituições e avaliações de mérito. A escrita, na verdade, acaba sendo um dos filtros mais fortes na instituição acadêmica, dado o seu valor social e o uso que dela é feito nas relações hierárquicas entre estudantes e professores, entre pesquisadores e seus avaliadores.

Pensar o ensino de escrita acadêmica só faz sentido se a escrita for compreendida desse modo e não como uma habilidade transparente e simplificada que pode ser ensinada de forma desvinculada do seu valor social no mundo acadêmico. Já se publicou bastante mostrando a falência de um ensino de escrita acadêmica voltado às habilidades linguísticas. Em seu artigo Student writing as 'academic literacies', Lillis (2003) critica as abordagens - que podem ser chamadas de tradicionais - do ensino de escrita acadêmica por terem uma perspectiva monológica, calcada no modelo autônomo de letramento, que tem, como uma de suas características, a perspectiva deficitária da escrita dos alunos. Por outro lado, embora reconheça que a perspectiva do modelo dos letramentos acadêmicos pode contribuir para a construção de alternativas a essa abordagem monológica, critica a falta de propostas.

Uma abordagem de ensino de escrita baseada no modelo dos letramentos acadêmicos enfatiza o caráter socialmente situado e a natureza ideológica da escrita acadêmica. Para construir sua proposta, Lillis (2003) parte dessa perspectiva e baseiase na concepção dialógica de Bakhtin, explicitando como entende essa concepção: além de ver o diálogo como central para a descrição da natureza da linguagem humana, também o vê como uma idealização de como a comunicação humana pode ser. Consequentemente, para Lillis, há dois níveis de diálogo na concepção de Bakhtin: o diálogo que é inerente a toda comunicação humana e o diálogo como um ideal a ser trabalhado, contra o monologismo. Lillis se baseia em alguns conceitos de Bakhtin para fazer essa distinção e justificar esse segundo nível: força centrípeta e centrífuga, discurso autoritário e discurso internamente persuasivo. Esse segundo nível de diálogo, então, contrasta com a concepção de monólogo que está presente na maioria das práticas de escrita de estudantes na academia.

A partir da análise de ensaios escritos por estudantes universitários em resposta a questões colocadas por seus professores, Lillis (2003), nesse artigo, mostra que há diálogo no primeiro nível por ela considerado, já que os estudantes respondem ao que lhes foi proposto. No entanto, não há no segundo nível e isso pode ser afirmado a partir das conversas sobre o texto que ela desenvolve junto aos estudantes e a partir da observação dos comentários do professor sobre os textos dos estudantes. Lillis mostra que não há diálogo entre o que o professor comenta, o que a aluna escreveu e o que ela diz sobre sua escrita, justificando-a. Esse é o que pode ser caracterizado como um ensino monológico. 
Diante dessa análise, Lillis propõe uma abordagem dialógica, nesse quadro, sendo essa abordagem compreendida como um objetivo a ser trabalhado, nas práticas de letramento acadêmicas, onde deverão estar presentes alguns princípios: olhar o texto do aluno como estando em processo e abrir espaço para conversas sobre o texto do aluno; abrir espaço para, no interior das disciplinas, aparecerem os interesses e questões particulares que se relacionam à disciplina, mas que tradicionalmente não têm espaço nas discussões acadêmicas; abrir espaço para outras formas de dizer - outros gêneros do discurso - e para as diferentes possibilidades que podem ser exploradas nesses gêneros.

Nessa perspectiva, ensinar ganha outros significados, os conhecimentos dos estudantes ganham outro status e a relação entre estudante e professor é alterada. São princípios decorrentes de uma atitude etnográfica que vão na contramão do que é tradicionalmente esperado com o ensino de escrita acadêmica, em que só um lado - o das convenções e padrões hegemônicos - tem seu lugar. Nessa perspectiva etnográfica, a voz do outro, do aluno, pode abrir possibilidades no ensino além daquelas que as análises dos textos dos alunos possibilitam.

\section{Concluindo: os ganhos e os limites de uma abordagem etnográfica para a pesquisa e o ensino}

Não há dúvidas de que as pesquisas sobre escrita acadêmica (e também de escritas de outros contextos, principalmente escolares) com base em uma abordagem etnográfica orientada pelo texto ainda são relativamente recentes em nosso contexto brasileiro de pesquisa. Não só devido à tradição de estudos baseados em teorias textuais e discursivas, mas também pelas características de pesquisas com abordagem etnográfica que exigem um preparo teórico-metodológico por parte do pesquisador, seguido de seu trabalho de campo propriamente, junto aos escritores e seus textos, preferencialmente em um percurso longitudinal. No entanto, essas pesquisas já têm mostrado ângulos sobre a escrita que nos permitem entendê-las melhor em suas peculiaridades e singularidades. As histórias de letramento associadas às histórias sobre o texto trazem informações que a análise do texto não traria, mesmo quando consideramos dados indiciais nas escritas. Trabalhos produzidos nessa direção apontam alguns resultados e também levantam dúvidas a serem perseguidas em pesquisas futuras. As teses de doutorado de PasquotteVieira (2014) e Miranda (2016) são exemplos de análises nessa direção.

Por outro lado, em relação ao ensino, os limites parecem maiores quando se observa tanto a inexistência de uma discussão, principalmente no contexto acadêmico, sobre uma política de ensino de escrita acadêmica, como a existência de cursos de escrita 
- Pesquisa e ensino de escrita: letramento acadêmico e etnografia

acadêmica com caráter remedial. Uma abordagem etnográfica para o ensino certamente trará mudanças aos modelos de ensino convencionais, que podem ser incluídos nas duas abordagens caracterizadas por Lea e Street (2006) como modelo de habilidades e modelo de socialização acadêmica. As mudanças irão na direção de se incluir metodologias como as conversas sobre os textos e as histórias de escrita como modos de conscientização sobre a escrita em uma perspectiva crítica e desvinculada da perspectiva do déficit da escrita. Nessa perspectiva, o papel dos mediadores de letramento não necessariamente é exercido por um professor e a função do mediador não é corrigir, mas acompanhar os estudantes e reconhecer suas escritas como possibilidades no percurso de inserção acadêmica.

\section{Referências}

ANDRADE, L. T. O professor alfabetizador imantado entre propostas teóricas: o letramento e a metodologia do fônico. In: SEMINÁRIO INTERNACIONAL SOBRE HISTÓRIA DO ENSINO DE LEITURA E ESCRITA. A CONSTITUIÇÃO DO CAMPO DA HISTÓRIA DA ALFABETIZAÇÃO NO BRASIL, 2010, Marília. Anais... Marília: UNESP, 2010.

BARTON, D. Literacy: An Introduction to the Ecology of Written Language. London: Blackwell, 1994.

BLOMMAERT, J. Ethnography as counter-hegemony: Remarks on epistemology \& method. Working Papers in Urban Language and Literacies, London, v. 34, p. 01-08, 2006.

CARON, M. F. et al. A produção acadêmica sobre aquisição e ensino da escrita. Estudos Linguísticos, Assis, v. XXIX, p. 492-497, 2000.

FIAD, R. S. Algumas considerações sobre os letramentos acadêmicos no contexto brasileiro. Pensares em Revista, São Gonçalo, v. 6, p. 23-34, 2015.

FIAD, R. S. Reescrita, Dialogismo e Etnografia. Revista Linguagem (em) Discurso, Tubarão, v. 13, n. 3, p. 463-480, set./dez. 2013.

GEE, J. P. Social linguistics and literacies: ideology in Discourses. 2. ed. London, Philadelphia: The Farmer Press, 1996.

GERALDI, J. W.; SILVA, L. L. M.; FIAD, R. S.. Linguística, ensino de língua materna e formação de professores. D.E.L.T.A., São Paulo, v. 12, n. 2, p. 307-326, 1996.

GOMES-SANTOS, S. N. A questão do gênero no Brasil: teorização acadêmico-científica e normatização oficial. 2004. 251 f. Tese (Doutorado em Linguística) - Instituto de Estudos da Linguagem, Universidade Estadual de Campinas, Campinas, 2004. 
IVANIC, R. Writing and identity. The discoursal construction of identity in academic writing. Amsterdam/Filadelfia: John Benjamins Publishing Company, 1998.

LEA, M. R.; STREET, B. V. The 'Academic Literacies' Model: Theory and Applications, Theory into Practice, v. 45, n. 4, p. 368-377, 2006.

LILLIS, T. Student Writing as 'Academic Literacies': Drawing on Bakhtin to Move from Critique to Design. Language and Education, v. 17, n. 3, p. 192-207, 2003.

. Ethnography as Method, Methodology, and "Deep Theorizing". Closing the Gap Between Text and Context in Academic Writing Research. Written Communication, v. 25, p. 353-388, 2008.

Bringing writers' voices to writing research: Talk around texts. In: CARTER, A.; LILLIS, T.; PARKIN, S. Why writing matters. Issues of Access and identity in writing research and pedagogy. Amsterdam/Filadelfia: John Benjamins Publishing Company, 2009. p. 169-187.

LILLIS, T.; CURRY, M. J. Academic writing in a global context. The politics and practices of publishing in English, Londres, Routledge, 2010.

MIRANDA, F. D. S. Letramentos (en)formados por relações dialógicas na universidade: (res)significações e refrações com tecnologias digitais. 2016. $414 \mathrm{f}$. Tese (Doutorado em Linguística Aplicada) - Instituto de Estudos da Linguagem, Universidade Estadual de Campinas, Campinas, 2016.

OSAKABE, H. Redações no vestibular: provas de argumentação. Cadernos de Pesquisa, v. 23, p. 51-59, 1977.

PASQUOTTE-VIEIRA, E. A. Letramentos acadêmicos: (re)significações e (re) posicionamentos de sujeitos discursivos. 2014. 262 f. Tese (Doutorado em Linguística Aplicada) - Instituto de Estudos da Linguagem, Universidade Estadual de Campinas, Campinas, 2014.

PÉCORA, A. A. B. Redações no vestibular: estudo do período: uma proposta pragmática. Cadernos de Pesquisa, v. 23, p. 29-36, 1977.

PIETRI, E. de. A constituição da escrita escolar em objeto de análise dos estudos linguísticos. Trabalhos em Linguística Aplicada, Campinas, v. 46, n. 2, p. 283-297, 2007.

STREET, B. V. Literacy in theory and practice. London: Cambridge University Press, 1984. 
- Pesquisa e ensino de escrita: letramento acadêmico e etnografia

COMO CITAR ESTE ARTIGO: FIAD, Raquel Salek. Writing teaching and research: academic literacy and ethnography. Revista do GEL, v. 14, n. 3, p. 86-99, 2017. Disponível em: https://revistadogel.gel.org.br/.

DOI: $\underline{\text { http://dx.doi.org/10.21165/gel.v14i3.1867 }}$

Submetido em: 18/07/2017. | Aceito em: 08/11/2017. 